\title{
Measuring benefits and patients' satisfaction when glasses are not needed after cataract and presbyopia surgery: scoring and psychometric validation of the Freedom from Glasses Value Scale $\left(\right.$ FGVS $\left.^{\odot}\right)$
}

Gilles Berdeaux¹, Juliette Meunier*2, Benoit Arnould² and Muriel Viala-Danten²

\begin{abstract}
Background: The purpose of this study was to reduce the number of items, create a scoring method and assess the psychometric properties of the Freedom from Glasses Value Scale (FGVS), which measures benefits of freedom from glasses perceived by cataract and presbyopic patients after multifocal intraocular lens (IOL) surgery.

Methods: The 21-item FGVS, developed simultaneously in French and Spanish, was administered by phone during an observational study to 152 French and 152 Spanish patients who had undergone cataract or presbyopia surgery at least 1 year before the study. Reduction of items and creation of the scoring method employed statistical methods (principal component analysis, multitrait analysis) and content analysis. Psychometric properties (validation of the structure, internal consistency reliability, and known-group validity) of the resulting version were assessed in the pooled population and per country.
\end{abstract}

Results: One item was deleted and 3 were kept but not aggregated in a dimension. The other 17 items were grouped into 2 dimensions ('global evaluation', 9 items; 'advantages', 8 items) and divided into 5 sub-dimensions, with higher scores indicating higher benefit of surgery. The structure was validated (good item convergent and discriminant validity). Internal consistency reliability was good for all dimensions and sub-dimensions (Cronbach's alphas above 0.70). The FGVS was able to discriminate between patients wearing glasses or not after surgery (higher scores for patients not wearing glasses). FGVS scores were significantly higher in Spain than France; however, the measure had similar psychometric performances in both countries.

Conclusions: The FGVS is a valid and reliable instrument measuring benefits of freedom from glasses perceived by cataract and presbyopic patients after multifocal IOL surgery.

\section{Background}

Cataracts and presbyopia are both conditions that cause visual impairment. Cataracts, responsible for almost half the cases of blindness worldwide [1], are cloudy areas of accumulated protein that form on the lens of the eye, causing blurred and reduced vision, faded color perception, glare, light sensitivity and impaired night vision.

\footnotetext{
* Correspondence: juliette.meunier@mapivalues.com

2 Statistics and Psychometrics, Mapi Values, 27, rue de la Villette, 69003 Lyon, France

Full list of author information is available at the end of the article
}

Presbyopia is the loss of the natural lens' flexibility, which makes it difficult to focus on close objects. Age is the major cause of development for both cataracts and presbyopia. Many aspects of patients' daily lives are affected by these two conditions, and there is increasing interest in evaluating their impacts on patients' quality of life [26].

Surgery, consisting of the replacement of the natural lens by an intraocular lens (IOL), is the only effective treatment for cataracts [7]. More recently, presbyopiacorrecting lenses have been used to treat presbyopia in 
patients undergoing cataract surgery $[8,9]$. The benefits of cataract surgery for patients' visual functioning, satisfaction and quality of life are well-documented in the literature $[4,10-16]$. Monofocal IOL implantation allows either distance or near vision to be corrected, so patients with both problems still need to wear glasses to correct the one or the other visual impairment. Multifocal IOLs were then developed to restore both distance and near vision and, consequently, to free patients from glasses.

Several multifocal intraocular implants have been specifically designed as an option for cataract surgery lens replacement, as well as for patients with presbyopia. Their safety and efficacy, as well as benefit for visual functioning and patient satisfaction, are well-reported in the literature [10,14,16-25]. However, the value for patients of no longer requiring glasses has not been specifically documented. Typical measures used to assess the benefit of IOLs include clinical parameters, a functional test of visual acuity and some functional Patient-Reported Outcome (PRO) scales (e.g. TyPE questionnaire [26], Visual Function Index (VF-14) [27]). Some other PRO scales were specifically designed to measure the impact of assistive devices or correction - either with glasses or contact lenses - on patients' quality of life (e.g. Quality of Life Impact of Refractive Correction questionnaire (QIRC) [28], Contact Lens Impact on Quality of Life (CLIQ) [29], Psychosocial Impact of Assistive Devices (PIADs) [30]). To our knowledge, no existing PRO scales assess the perceived patient benefit of freedom from glasses. A specific questionnaire, the Freedom from Glasses Value Scale (FGVS $\odot$ ), was developed [31] for this purpose and administered to French and Spanish patients during an observational study.

The objectives of this paper are to present the item reduction process and creation of the scoring method for the FGVS, and then to assess the psychometric properties of the resulting version of the measure.

\section{Methods \\ The FGVS}

The FGVS was developed simultaneously in French and Spanish following patient interviews and the development of a conceptual framework comprising 9 global concepts identified from analysis of the exploratory patient interviews [31]. Based on these concepts, 21 items were generated: global vision (1 item), impact of eye surgery on patients' lives (1 item), practical constraints related to wearing glasses ( 1 item), improvement of practical issues without glasses (8 items), improvement of psychological constraints without glasses (5 items), physical appearance/aesthetic aspect (self image) (1 item), physical appearance/aesthetic aspect (in the eyes of others) (1 item), eyesight problems left behind ( 1 item) and recommendation of surgery to others ( 2 items). All items had 5-point Likert response scales, ranging from "much better" to "much worse", "very positive" to "very negative", "no, not at all" to "yes, absolutely", "totally agree" to "totally disagree" or "definitely better without glasses" to "definitely better with glasses".

\section{Patients and study design}

An observational, cross-sectional, non-comparative, multicentre study was conducted in France and Spain between June 2007 and January 2008 involving patients who had a ReSTOR lens implanted in both eyes, with the last eye operated at least 1 year before the inclusion date. Centres were selected from each country in which surgeons were experienced ReSTOR users and had implanted numerous lenses in the preceding 18 months. Patients included were all over 49 years old, with agerelated cataract or bilateral presbyopia. They had cataract or presbyopia surgery using phaco-emulsification with IOL implantation in the posterior chamber resulting in post-operative emmetropia. None had refractive surgery before the ReSTOR lens implantation (i.e. LASIK and PRK) or a ReSTOR lens implanted as part of a clinical trial. None had intra-operative difficulties that required them to later wear glasses, post-operative complications necessitating a refractive correction, or concomitant ocular diseases at the time of surgery deteriorating the visual acuity prognosis. Patients meeting the inclusion criteria were selected from an exhaustive list of cases. The target sample included about 150 patients per country. In addition to refining and assessing the psychometric properties of the FGVS, another objective of this study was to find the percentage of ReSTOR IOL patients who do not need glasses 1 year after cataract or presbyopia surgery, and to explore patients' degree of satisfaction with this technology.

The FGVS was administered by phone. Information about patients' use of glasses before and after surgery was collected. Patients' age and gender, clinical characteristics before surgery (general and ocular co-morbidities), vision before surgery, and related information after surgery (posterior capsular opacification, refractive surgery, other ocular diseases) were collected from patient charts.

This study was conducted in compliance with the ethical principles derived from the Declaration of Helsinki, the ADELF (the Association of the French-speaking epidemiologists) and the Good Epidemiology Practices. All patients participating in the study signed a written consent prior to their inclusion. This study received approval of the CNIL (the French data protection permanent committee, authorization $\mathrm{N}^{\circ}$ 907054), the CCTIRS (the French advisory committee dealing with data processing on health research) and the CNOM (the French council of the college of physicians) for France. This study also received approval of the AEMPS (the Spanish agency of 
drugs and health products) and Comité Ético de Investigación Clínica Regional del Principado de Asturias (the ethical committee of clinical research of the Principality of Asturias) for Spain.

\section{Statistical analyses \\ Analysis population}

The analysis population included all patients for whom the FGVS was completed and considered assessable (i.e. at least $50 \%$ of the items were completed). Unless otherwise specified, all statistical analyses were performed on these patients overall as well as by country with a comparison of results between countries.

\section{Item reduction and creation of the scoring method for the FGVS}

The quality of completion of the FGVS was first analyzed for all FGVS questionnaires received. Item reduction and creation of the scoring method were then conducted using data from patients who completed all FGVS items. Three statistical methods were used to define the structure of the FGVS. First, a Principal Component Analysis (PCA) with varimax rotation was performed to identify the structure of the questionnaire; the retained factors were those with an eigenvalue greater than 1 . The structure of the questionnaire was compared between countries, and items not loading on the same scale in both countries were considered for deletion. Second, a multitrait analysis was performed to explore and confirm the structure identified by the PCA. Item convergent and discriminant validity [32] were analyzed (item convergent validity criterion: the correlation between each item and its own hypothesized scale should be higher than 0.40; item discriminant validity criterion: each item should correlate more highly with its own hypothesized scale than with the other scales). Items not loading well on their hypothesized scale were considered for deletion. Lastly, Cronbach's alpha [33] for each scale was analyzed, with a recommended value of at least 0.70 [34]. In addition to using these statistical methods, the final structure of the FGVS was defined based on the content of the items.

\section{Psychometric properties of the FGVS}

A multitrait analysis was conducted on the analysis population to validate the structure of the FGVS created using the previous analyses. The internal consistency of the FGVS was assessed using Cronbach's alpha for each scale. Percentages at floor and at ceiling were checked to ensure there were no issues related to a high percentage of patients having the lowest or the highest possible score. Known-group validity of the FGVS (the extent to which the FGVS is able to detect variability among patients who are known to differ on various parameters) was analyzed by comparing all scores between subgroups of patients based on wearing glasses before and after surgery, other ocular diseases since surgery, age, gender and country.

\section{Statistical tests, level of significance and software}

A chi-square test was used when comparing a categorical variable between subgroups of patients. A Mann-Whitney-Wilcoxon test was used when comparing a continuous variable between 2 subgroups of patients. A KruskalWallis test was employed when comparing a continuous variable between more than 2 subgroups of patients. The threshold for statistical significance was fixed at 5\%. All analyses were performed using SAS software for Windows (Version 9; SAS Institute, Inc., Cary, NC, USA).

\section{Results}

\section{Patients' characteristics}

Among the 346 patients approached to participate in the study, the 304 patients finally included in the study were kept in the analysis population as they all completed at least $50 \%$ of FGVS items. The mean age was 66 , with a majority of females (66\%). Before surgery, two-thirds of patients had hyperopia (67\%), about half had astigmatism $(49 \%)$ and about a quarter had myopia (28\%). About $16 \%$ of the patients had ReSTOR implanted for presbyopia. Only $7 \%$ of the patients did not have to wear glasses before surgery, whereas $87 \%$ were independent from glasses after surgery. A large majority of patients did not develop new eye disease and did not present posterior capsular opacification 1 year after surgery (93\% and 85\% respectively).

As shown in Table 1, the 152 French and 152 Spanish patients were comparable regarding age, gender, wearing glasses before and after surgery, and development of other ocular disease after surgery. However, statistically significant differences were observed between France and Spain in the percentages of patients with myopia, hyperopia and astigmatism before surgery; there was a higher percentage of patients with myopia and astigmatism in Spain, and a higher percentage of patients with hyperopia in France.

\section{Quality of completion}

The quality of completion of the FGVS was very good, with only 9 missing data (3\%) observed both for item 17 ("self-image") and item 18 ("other people's image of you"). These missing data were for French patients; no missing data were observed for Spanish patients.

\section{Distribution of FGVS items}

For each of the 21 FGVS items, the majority of patients answered positively (more comfort, less worry, less bother, etc.), with the percentage of positive answers ranging from $51 \%$ for item 18 "other people's image of you" to $93 \%$ for item 2 "change in life since operation" (Table 2). Spanish patients tended to answer more posi- 
Table 1: Patients' characteristics per country ( $n=152$ for France, $n=152$ for Spain).

\begin{tabular}{|c|c|c|c|c|}
\hline & & France $(n=152)$ & Spain $(n=152)$ & $\begin{array}{l}\text { p-value of the } \\
\text { difference }\end{array}$ \\
\hline \multicolumn{5}{|c|}{ Patients' socio-demographic characteristics } \\
\hline \multirow[t]{2}{*}{ Age (years) } & Mean (STD) & $65(7.5)$ & $67(8.9)$ & 0.166 \\
\hline & Median (min - max) & $66(51-80)$ & $66(51-83)$ & \\
\hline Gender & Males (\%) & 36 & 32 & 0.468 \\
\hline \multicolumn{5}{|c|}{ Patients' characteristics before surgery } \\
\hline & Myopia (\%) & 22 & 34 & 0.010 \\
\hline \multirow[t]{3}{*}{ Patients' vision** } & Hyperopia (\%) & 74 & 59 & 0.012 \\
\hline & Astigmatism (\%) & 35 & 63 & $<0.001$ \\
\hline & Yes, multifocals (\%) & 59 & 60 & \\
\hline \multirow[t]{3}{*}{ Wearing glasses } & Yes, single vision (\%) & 36 & 30 & 0.237 \\
\hline & Yes, unknown type (\%) & 2 & 1 & \\
\hline & No (\%) & 4 & 9 & \\
\hline \multirow{2}{*}{$\begin{array}{l}\text { Best corrected visual } \\
\text { acuity }\end{array}$} & Mean (STD) & $0.8(0.2)$ & $0.7(0.2)$ & $<0.001$ \\
\hline & Median (min - $\max )$ & $0.9(0.3-1.2)$ & $0.8(0.1-1.0)$ & \\
\hline
\end{tabular}

Patients' characteristics after surgery

\begin{tabular}{|c|c|c|c|c|}
\hline \multirow{3}{*}{ Wearing glasses } & Yes, always (\%) & 3 & 7 & \multirow{3}{*}{0.138} \\
\hline & Yes, sometimes (\%) & 9 & 7 & \\
\hline & No/Never (\%) & 88 & 86 & \\
\hline \multicolumn{2}{|c|}{ Other ocular disease (\%) } & 7 & 7 & 0.821 \\
\hline
\end{tabular}

tively than French patients, whatever the item (percentage of positive answers ranging from $57 \%$ to $95 \%$ with a mean of $77 \%$ for Spanish patients; percentage of positive answers ranging from $39 \%$ to $93 \%$ with a mean of $69 \%$ for French patients). Spanish patients also used the central answer choice more often than French patients (mean percentage of central answer: $18 \%$ for Spanish patients; $10 \%$ for French patients), whereas French patients used the intermediate answer choices (answers 2 or 4 over a 15 range) more often (mean percentage of intermediate answers: $36 \%$ for French patients; $11 \%$ for Spanish patients).

\section{Item reduction and creation of the scoring method for the FGVS}

The item reduction was conducted using data from the 295 patients who completed all FGVS items (143 in France and 152 in Spain). As shown in Table 3, the PCA conducted on the 21 FGVS items resulted in four factors with an eigenvalue greater than 1, explaining $66 \%$ of the total variance. Item 15 ("feel younger since operation") was deleted from the questionnaire as it loaded on several scales with the global PCA, and did not load on the same scale with PCAs conducted on French and Spanish patients separately. The final structure of the question- 
Table 2: Patients' answers to the FGVS items $(\mathrm{N}=304)$.

\begin{tabular}{|c|c|c|c|}
\hline Content of FGVS $\odot$ items & Positive answers (\%) & Central answer (\%) & Negative answers (\%) \\
\hline 1. Evaluation of eyesight since operation & 88.16 & 5.59 & 6.25 \\
\hline 2. Change in life since operation & 93.09 & 2.96 & 3.95 \\
\hline 3. Bother of wearing glasses & 78.95 & 6.25 & 14.80 \\
\hline \multicolumn{4}{|l|}{ Stop wearing glasses because... } \\
\hline 4. Lenses steaming up & 61.18 & 22.37 & 16.45 \\
\hline 5. Sliding down nose & 61.84 & 21.38 & 16.78 \\
\hline 6. Cleaning lenses & 70.07 & 17.11 & 12.83 \\
\hline 7. Frames restrictive & 51.97 & 22.37 & 25.66 \\
\hline 8. No worry about breaking glasses & 59.87 & 17.76 & 22.37 \\
\hline 9. No worry about scratching glasses & 61.18 & 18.42 & 20.39 \\
\hline 10. No worry about losing glasses & 64.14 & 14.80 & 21.05 \\
\hline 11. Pressing on nose & 60.86 & 19.41 & 19.74 \\
\hline \multicolumn{4}{|l|}{ Feelings since operation... } \\
\hline 12. Comfort & 89.14 & 5.26 & 5.59 \\
\hline 13. Freedom & 90.79 & 4.28 & 4.93 \\
\hline 14. Well-being & 87.83 & 6.58 & 5.59 \\
\hline 15. Youth & 60.20 & 21.05 & 18.75 \\
\hline 16. Having new eyes & 74.34 & 11.18 & 14.47 \\
\hline 17. Self-image & 70.39 & 19.74 & 6.91 \\
\hline 18. Other people's image of you & 50.66 & 41.78 & 4.61 \\
\hline 19. Eyesight problems in the past & 77.96 & 11.18 & 10.86 \\
\hline 20. Willingness to undergo surgery again & 89.80 & 2.96 & 7.24 \\
\hline 21. Willingness to recommend to others & 88.49 & 3.95 & 7.57 \\
\hline
\end{tabular}

naire, presented in Table 4, uses 20 of the 21 original FGVS items. Items 3 ("bother of wearing glasses"), 17 ("self-image") and 18 ("other people's image of you"), corresponding to the fourth factor of the PCA, were kept but not aggregated in a dimension. Item 3 loaded on several scales. The content of items 17 and 18 was considered off-topic as they did not refer to the surgery or advantages of freedom from glasses, and missing data were observed for these 2 items in French patients. However, as these 3 items might be good predictors of the patients' motivation for surgery, these items were retained in the questionnaire. The other 17 items were grouped into 2 dimensions ('global evaluation', 9 items; 'advantages', 8 items). This structure, based on the results of the PCA, was confirmed by the results of the multitrait analysis, with all items meeting both the convergent and discriminant validity criteria, and the Cronbach's alpha values of each dimension exceeding 0.70 . The 2 dimensions were then divided into 5 sub-dimensions based on the content of the items: 'global evaluation' was divided into 'evaluation of the result' (2 items), 'feelings' (4 items) and 'global judgment' (3 items); 'advantages' was divided into 'psychological advantages' (3 items) and 'practical advantages' (5 items). The results of the multitrait analysis for these 5 sub-dimensions were good, with all items meeting the convergent validity criterion and only a few items not meeting the discriminant validity criterion. The Cronbach's alpha was above 0.70 for the 5 sub-dimensions. Scale-scale correlations between the 5 sub-dimensions ranged between 0.27 and 0.66 , indicating a link but no redundancy between the sub-dimensions, reinforcing the decision to keep them in the final structure of the FGVS.

In terms of calculation of scores, all item scales were reversed so that a higher item score reflects a more positive answer. A score was then calculated for each dimension and sub-dimension as the mean of reversed items in the dimension/sub-dimension. All dimension and subdimension scores ranged from 1 to 5 , with a higher score indicating a more positive evaluation and greater advantages of freedom from glasses. To handle missing data, sub-dimension scores were calculated if at least 1 item of the sub-dimension was completed, and dimension scores 
Table 3: Results of the PCA conducted on FGVS items ( $N=295)$.

\begin{tabular}{|c|c|c|c|c|}
\hline & Factor 1 & Factor 2 & Factor 3 & Factor 4 \\
\hline Eigenvalue for each factor & 8.51 & 2.98 & 1.32 & 1.11 \\
\hline Proportion of variance explained by each factor & 0.41 & 0.14 & 0.06 & 0.05 \\
\hline \multicolumn{5}{|l|}{ Factor loadings for each item: } \\
\hline 2. Change in life since operation & 0.84 & 0.21 & 0.03 & 0.07 \\
\hline 12. Feelings since operation... Comfort & 0.84 & 0.14 & 0.22 & 0.20 \\
\hline 20. Willingness to undergo surgery again & 0.83 & 0.11 & 0.01 & 0.01 \\
\hline 14. Feelings since operation... Well-being & 0.82 & 0.11 & 0.18 & 0.30 \\
\hline 13. Feelings since operation... Freedom & 0.82 & 0.08 & 0.17 & 0.26 \\
\hline 19. Eyesight problems in the past & 0.76 & 0.11 & 0.15 & 0.10 \\
\hline 21. Willingness to recommend to others & 0.76 & 0.07 & 0.07 & 0.06 \\
\hline 1. Evaluation of eyesight since operation & 0.73 & 0.23 & -0.03 & -0.07 \\
\hline 16. Feelings since operation... Having new eyes & 0.68 & 0.13 & 0.20 & 0.25 \\
\hline 15. Feelings since operation... Youth & 0.55 & 0.12 & 0.13 & 0.41 \\
\hline 10. Stop wearing glasses because... No worry about losing glasses & 0.14 & 0.86 & 0.10 & 0.15 \\
\hline 8. Stop wearing glasses because... No worry about breaking glasses & 0.21 & 0.83 & 0.22 & 0.10 \\
\hline 9. Stop wearing glasses because... No worry about scratching glasses & 0.17 & 0.80 & 0.33 & 0.10 \\
\hline 11. Stop wearing glasses because... Pressing on nose & 0.15 & 0.57 & 0.27 & 0.19 \\
\hline 7. Stop wearing glasses because... Frames restrictive & 0.20 & 0.51 & 0.44 & 0.11 \\
\hline 5. Stop wearing glasses because... Sliding down nose & 0.11 & 0.20 & 0.79 & 0.16 \\
\hline 6. Stop wearing glasses because... Cleaning lenses & 0.17 & 0.29 & 0.78 & 0.13 \\
\hline 4. Stop wearing glasses because... Lenses steaming up & 0.09 & 0.33 & 0.74 & -0.05 \\
\hline 17. Self-image & 0.20 & 0.13 & 0.00 & 0.83 \\
\hline 18. Other people's image of you & 0.14 & 0.21 & 0.09 & 0.69 \\
\hline 3. Bother of wearing glasses & -0.14 & -0.09 & -0.41 & -0.50 \\
\hline
\end{tabular}

were calculated only if all corresponding sub-dimensions were scored.

\section{Psychometric properties of the FGVS}

As presented in Table 5, the multitrait analyses conducted on the overall analysis population to validate the 2 dimensions and 5 sub-dimensions of the FGVS showed that all items met the convergent validity criterion. Only a few items did not meet the discriminant validity criterion ( 1 item in the 'evaluation of the result' sub-dimension, 1 item in the 'global judgment' sub-dimension and 1 item in the 'practical advantages' sub-dimension). The Cronbach's alpha was higher than the recommended 0.70 threshold for the 2 dimensions ( 0.93 for 'global evaluation' and 0.89 for 'advantages'), as well as for all subdimensions (ranging from 0.78 for 'evaluation of the result' to 0.91 for 'feelings'), indicating good internal consistency reliability. A ceiling effect was observed for the 2 dimension scores (32.2\% for 'global evaluation' and $18.4 \%$ for 'advantages'), as well as for all sub-dimension scores (ranging from $20.1 \%$ for 'psychological advantages' to $56.6 \%$ for 'evaluation of the result'). No floor effect was observed, either for the 2 dimension scores or for the 5 sub-dimension scores. Similar results were found in France and Spain.

Patients not wearing glasses after surgery reported higher 'global evaluation' and 'advantages' dimension scores (mean score of 4.6 and 3.9 respectively), indicating a better global evaluation and greater advantages than patients wearing glasses (mean scores lower than 4.0 and 3.5, respectively). As shown in Table 6, these differences 
Table 4: Final structure of the FGVS.

\begin{tabular}{|c|c|c|c|}
\hline \multicolumn{2}{|c|}{ Item } & \multirow[t]{2}{*}{ Sub-dimension } & \multirow[t]{2}{*}{ Dimension } \\
\hline Number & Label & & \\
\hline 1 & $\begin{array}{l}\text { Evaluation of eyesight since } \\
\text { operation }\end{array}$ & Evaluation of the result & \multirow{10}{*}{ Global evaluation } \\
\hline \multirow[t]{2}{*}{2} & Change in life since operation & & \\
\hline & Feelings since operation & & \\
\hline 12 & ... Comfort & & \\
\hline 13 & ... Freedom & Feelings & \\
\hline 14 & ... Well-being & & \\
\hline 16 & ... Having new eyes & & \\
\hline 19 & Eyesight problems in the past & & \\
\hline 20 & $\begin{array}{l}\text { Willingness to undergo } \\
\text { surgery again }\end{array}$ & Global judgment & \\
\hline \multirow[t]{2}{*}{21} & $\begin{array}{l}\text { Willingness to recommend to } \\
\text { others }\end{array}$ & & \\
\hline & Stop wearing glasses because & & \multirow{9}{*}{ Advantages } \\
\hline 4 & ... Lenses steaming up & & \\
\hline 5 & ... Sliding down nose & Practical & \\
\hline 6 & ... Cleaning lenses & advantages & \\
\hline 7 & ... Frames restrictive & & \\
\hline 11 & ... Pressing on nose & & \\
\hline 8 & $\begin{array}{l}\text {... No worry about breaking } \\
\text { glasses }\end{array}$ & \multirow{3}{*}{$\begin{array}{l}\text { Psychological } \\
\text { advantages }\end{array}$} & \\
\hline 9 & $\begin{array}{l}\text {... No worry about scratching } \\
\text { glasses }\end{array}$ & & \\
\hline 10 & $\begin{array}{l}\text {... No worry about losing } \\
\text { glasses }\end{array}$ & & \\
\hline 3 & Bother of wearing glasses & \multirow{3}{*}{\multicolumn{2}{|c|}{ Not aggregated in a dimension }} \\
\hline 17 & Self-image & & \\
\hline 18 & Other people's image of you & & \\
\hline
\end{tabular}

were statistically significant, and the differences in the 5 sub-dimension scores were also statistically significant between those patients, with higher scores for patients not wearing glasses after surgery. Patients with no ocular co-morbidity after surgery reported a higher 'global evaluation' score (mean 4.5), indicating a better global evaluation, than those with an ocular co-morbidity after surgery $(n=21$, mean score of 3.8). This difference was statistically significant. Regarding the 'global evaluation' dimension, only the difference in the 'evaluation of the result' sub-dimension score was statistically significant between those patients, with a higher score for patients who did not develop another ocular disease after surgery. The comparison of the FGVS sub-dimension and dimension scores between groups of patients based on the wearing of glasses before surgery, age and gender had non-significant results. Statistically significant differences in 'global evaluation' and 'advantages' dimension scores and the 5 sub-scores were observed between France and Spain, with higher scores for Spanish patients, indicating a better global evaluation and greater advantages. 
Table 5: Psychometric validation of the final structure of the FGVS $(\mathrm{N}=304)$.

\begin{tabular}{|c|c|c|c|c|c|c|c|}
\hline & $\begin{array}{l}\text { Number of } \\
\text { items }\end{array}$ & $\%$ at floor & $\%$ at ceiling & $\begin{array}{c}\text { Range of } \\
\text { Spearman } \\
\text { item-scale } \\
\text { correlations }\end{array}$ & $\begin{array}{l}\% \text { of items } \\
\text { meeting the } \\
\text { convergent } \\
\text { validity } \\
\text { criterion }\end{array}$ & $\begin{array}{l}\text { \% of items } \\
\text { meeting the } \\
\text { discriminant } \\
\text { validity } \\
\text { criterion* }\end{array}$ & $\begin{array}{c}\text { Cronbach's } \\
\text { alpha }\end{array}$ \\
\hline $\begin{array}{l}\text { Evaluation of } \\
\text { the result }\end{array}$ & 2 & 0.3 & 56.6 & $0.57-0.57$ & $100 \%$ & $50 \%$ & 0.78 \\
\hline Feelings & 4 & 2.0 & 47.7 & $0.66-0.77$ & $100 \%$ & $100 \%$ & 0.91 \\
\hline $\begin{array}{l}\text { Global } \\
\text { judgment }\end{array}$ & 3 & 2.0 & 55.3 & $0.54-0.60$ & $100 \%$ & $67 \%$ & 0.84 \\
\hline $\begin{array}{l}\text { Global } \\
\text { evaluation }\end{array}$ & 9 & 0.3 & 32.2 & $0.52-0.75$ & $100 \%$ & $100 \%$ & 0.93 \\
\hline $\begin{array}{l}\text { Practical } \\
\text { advantages }\end{array}$ & 5 & 1.0 & 20.1 & $0.55-0.65$ & $100 \%$ & $80 \%$ & 0.82 \\
\hline $\begin{array}{l}\text { Psychological } \\
\text { advantages }\end{array}$ & 3 & 3.3 & 40.8 & $0.79-0.85$ & $100 \%$ & $100 \%$ & 0.89 \\
\hline Advantages & 8 & 0.3 & 18.4 & $0.58-0.81$ & $100 \%$ & $100 \%$ & 0.89 \\
\hline
\end{tabular}

\section{Discussion}

The FGVS, which measures benefits of freedom from glasses perceived by cataract and presbyopic patients after multifocal IOL surgery, was administered to French and Spanish patients who had had a ReSTOR lens implanted in both eyes, with the last lens implanted at least 1 year before inclusion in the study. The large majority of patients included in the study had ReSTOR implanted for cataracts. Subjective refraction parameters before surgery were not collected and the high hyperopia incidence rate is likely to include a majority of mild hyperopia. This high rate of hyperopia might influence the spectacle independence rate. This possible selection bias can only be definitely addressed using a randomized clinical trial. The FGVS was well accepted by all patients as very few missing data were observed. Only a small percentage of French patients did not answer when they were asked about their physical appearance and aesthetic aspects (i.e. preference with or without glasses).

The final version of the FGVS showed good psychometric properties, including good item convergent and discriminant validity and good internal consistency reliability of the dimensions as well as sub-dimensions. The FGVS was also able to discriminate between patients according to the wearing of glasses after surgery and according to the occurrence of another ocular disease after surgery. Patients not wearing glasses after surgery reported a more positive evaluation and greater advan- tages of freedom from glasses than those who had to wear glasses, and patients who had no other ocular disease after surgery reported a more positive evaluation of surgery than those who had ocular disease. Similar psychometric results were observed for France and Spain. These results demonstrate the validity of the final structure of the FGVS.

Along with good psychometric results, a noteworthy result of this study was the difference observed between French and Spanish patients in their response patterns. Spanish patients tended to answer more positively than French patients to all FGVS items, and were more likely to use the central answer choice than French patients. French patients were more likely to use the intermediate answer choices. Spanish patients tended to report a better global evaluation of surgery and greater advantages of freedom from glasses than French patients. This produced a statistically significant difference between countries in both scores. Three arguments could be put forward to explain these differences: issues with crosscultural performances of the French and Spanish versions of the FGVS, differences in the clinical status of French and Spanish patients, or cultural and social differences between France and Spain. First, one could argue that the differences observed between French and Spanish patients could be due to issues related to the cross-cultural validity of the FGVS, such as construct or item bias. However, the PCA found that the 2 versions had similar 
Table 6: Known-group validity: results for groups presenting a statistically significant difference in FGVS 'global evaluation' and/or 'advantages' score(s) $(\mathrm{N}=304)$.

\begin{tabular}{|c|c|c|c|c|c|c|c|c|c|}
\hline & & & \multicolumn{4}{|c|}{ Global evaluation scores } & \multicolumn{3}{|c|}{ Advantages scores } \\
\hline & & & \multirow[b]{2}{*}{$\begin{array}{l}\text { Dimension } \\
\text { score }\end{array}$} & \multicolumn{3}{|c|}{ Sub-dimension scores } & \multirow[b]{2}{*}{$\begin{array}{l}\text { Dimension } \\
\text { score }\end{array}$} & \multicolumn{2}{|c|}{ Sub-dimension scores } \\
\hline & & & & $\begin{array}{l}\text { Evaluation } \\
\text { of the } \\
\text { result }\end{array}$ & Feelings & $\begin{array}{c}\text { Global } \\
\text { judgment }\end{array}$ & & $\begin{array}{c}\text { Practical } \\
\text { advantages }\end{array}$ & $\begin{array}{l}\text { Psychological } \\
\text { advantages }\end{array}$ \\
\hline \multirow{7}{*}{$\begin{array}{l}\text { Wearing } \\
\text { glasses } \\
\text { after } \\
\text { surgery }\end{array}$} & Yes, always & Mean (STD) & $3.6(1.4)$ & $3.9(1.2)$ & $3.5(1.6)$ & $3.6(1.4)$ & $3.5(1.0)$ & $3.6(1.0)$ & $3.3(1.3)$ \\
\hline & $(\mathrm{N}=15)$ & Median & 4.6 & 4.5 & 4.8 & 4.3 & 3.8 & 3.6 & 3.0 \\
\hline & $\begin{array}{l}\text { Yes, } \\
\text { sometimes }\end{array}$ & Mean (STD) & $4.0(1.0)$ & $4.2(0.7)$ & $3.9(1.1)$ & $3.9(1.2)$ & $3.3(1.0)$ & $3.3(0.9)$ & $3.3(1.3)$ \\
\hline & $(N=24)$ & Median & 4.2 & 4.0 & 4.4 & 4.3 & 3.0 & 3.1 & 3.0 \\
\hline & No/Never & Mean (STD) & $4.6(0.7)$ & $4.6(0.7)$ & $4.5(0.8)$ & $4.6(0.8)$ & $3.9(1.0)$ & $3.9(1.0)$ & $3.9(1.2)$ \\
\hline & $(\mathrm{N}=265)$ & Median & 4.8 & 5.0 & 5.0 & 5.0 & 4.0 & 4.0 & 4.0 \\
\hline & $p$-value & & $<0.001$ & $<0.001$ & $<0.001$ & $<0.001$ & 0.006 & 0.007 & 0.017 \\
\hline \multirow{5}{*}{$\begin{array}{l}\text { Other } \\
\text { ocular } \\
\text { disease } \\
\text { since } \\
\text { surgery* }\end{array}$} & Yes & Mean (STD) & $3.8(1.6)$ & $3.9(1.3)$ & $3.6(1.7)$ & $3.8(1.7)$ & $3.4(1.1)$ & $3.5(1.1)$ & $3.3(1.4)$ \\
\hline & $(N=21)$ & Median & 4.7 & 4.5 & 4.8 & 4.7 & 3.3 & 3.6 & 3.0 \\
\hline & No & Mean (STD) & $4.5(0.7)$ & $4.6(0.7)$ & $4.5(0.8)$ & $4.5(0.8)$ & $3.8(1.0)$ & $3.8(1.0)$ & $3.8(1.2)$ \\
\hline & $(\mathrm{N}=283)$ & Median & 4.8 & 5.0 & 4.8 & 5.0 & 4.0 & 4.0 & 4.0 \\
\hline & $p$-value & & 0.044 & 0.023 & NS & NS & NS & NS & NS \\
\hline
\end{tabular}

* All 21 patients reported a different ocular disease since surgery, including for example conjunctivitis, problems with tears, sty or retinal detachment

Presented $p$-values are $\mathrm{p}$-values of the difference between groups (Mann-Whitney-Wilcoxon or Kruskal-Wallis test); NS, Not Significant

structures, and a quasi-systematic difference in the item responses was observed, indicating that issues with the cross-cultural validity of the FGVS is unlikely to be the major cause of these differences. Another explanation could be the difference in patients' clinical status. However, except in the proportion of myopic, astigmatic and hyperopic patients, French and Spanish patients were comparable, especially regarding the use of glasses before and after surgery. The most plausible explanation of the difference in the response patterns between French and Spanish patients in our study is the response style bias, defined as "a systematic tendency to respond to a range of questionnaire items on some other basis than the specific item content" [35]. Two highly problematic issues in attitude and survey research regarding response style bias are acquiescence and extreme response style [36,37]. In 2004, van Herk et al [38] showed that Spanish respondents tended to display higher acquiescence and to use more extreme responses than did French respondents, and our results are in line with those findings. The influence of some cultural characteristics of a society on the way that questions are answered has been explored and is well-known [39,40]. Thus the differences observed between French and Spanish patients in the present study, reinforced by the complexity of the role played by cultural features in the response style bias, suggest that the country effect should be systematically tested when using the FGVS.

A ceiling effect was observed for the 'global evaluation' score, which could be considered a limitation of our 
study. However, our study involved only patients who had no complications during surgery that required them to wear glasses and no post-surgery infectious complications. Therefore, all patients included were likely to be globally satisfied with surgery, and results may be different in a study based on a prospective study design. Another limitation of the present study is that some important psychometric properties, including concurrent validity, as well as reproducibility (test-retest reliability) and responsiveness, could not be assessed because the study design used only one PRO instrument and one evaluation. The psychometric validation of the FGVS should therefore be completed by using the questionnaire in another study in conjunction with other PRO instruments and with several different time point assessments. In addition, the questionnaire was administered by phone in our study; in future research the acceptability of the FGVS should also be analyzed when administered using another mode of administration. Lastly, additional work should assess the usefulness of the 3 items that were kept in the questionnaire but that did not load on either domain.

One could argue that our patient cohort was a mixed group of individuals suffering from different eye conditions which could affect patients' outcomes. Although patients with presbyopia might have different expectations than patients with cataract, the number of patients with presbyopia included in our survey was not big enough to allow any inferences. Moreover, the question of the relation between factors such as the age, gender or medical history, and expectations is still not resolved. Additional research with specific experimental designs should be conducted to confirm these findings.

In our study design, all FGVS items were completed after surgery. However, the structure of the final version of the FGVS, measuring on the one hand the advantages of no longer wearing glasses and evaluating on the other hand patients' satisfaction with the IOL surgery, suggests another potential future use of the questionnaire. The first part of the questionnaire on the advantages of freedom from glasses could be answered by patients before surgery in order to assess their expectations, while the second part on patients' satisfaction could be answered by patients after surgery in order to assess patients' satisfaction. Thus, the first part could be used for different purposes: first to describe the baseline expectations of patients, then as a covariate in the analysis of the benefit of surgery as measured by the 'global evaluation' score, and finally, alongside other clinical criteria, to document the patient's eligibility for surgery.

The final structure of the FGVS provides an overall view with its two 'global evaluation' and 'advantages' dimensions, as well as a more subtle view and particular perspective with its five sub-dimensions. Therefore, we recommend using a hierarchical process when analyzing FGVS data, by first evaluating the two dimension scores, and then, depending on the results obtained for dimension scores, evaluating the five sub-dimension scores.

\section{Conclusions}

Even though further validation analyses would be useful to complete the present study, the final version of the FGVS proved to be a reliable and valid PRO instrument that enables the practical and psychological advantages of freedom from glasses and patient satisfaction after multifocal IOL surgery to be assessed.

\section{Competing interests}

The present work was funded by Alcon, France SA, Rueil-Malmaison. Benoit Arnould, Juliette Meunier and Muriel Viala-Danten are paid consultants to Alcon. Gilles Berdeaux is an employee of Alconlabs.

\section{Authors' contributions}

All authors provided intellectual contributions to this manuscript. GB conceived the study and participated in the interpretation of data. JM designed and programmed statistical analyses, and participated in the interpretation of data. BA provided input in the interpretation of data and reviewed this manuscript. MVD participated in the design of statistical analyses and interpretation of data. All authors read and approved the final manuscript.

\section{Acknowledgements}

We would like to thank Hélène Gilet (Mapi Values) for writing this manuscript. The manuscript has been reviewed for its English by Sara Strzok.

Presented at the International Society for Pharmacoeconomics and Outcomes Research (ISPOR) 11th Annual European Congress, November 8-11 2008, Athens, Greece.

\section{Copyrights}

The FGVS ${ }^{\circ}$ is protected by copyright with all rights reserved to Alcon. Do not use without permission. For information on, or permission to use FGVS ${ }^{\circ}$, please contact the Mapi Research Trust, 27 rue de la Villette 69003 Lyon, France. Tel: +33 (0) 472136575 - E-mail:

trust@mapi.fr

- website: http://www.mapi-trust.org

\section{Author Details}

1 Health Economics Eurmea, Alcon Laboratories, 4, rue Henri Sainte-Claire Deville, 92563 Rueil-Malmaison Cedex, France and 2Statistics and

Psychometrics, Mapi Values, 27, rue de la Villette, 69003 Lyon, France

Received: 16 June 2009 Accepted: 24 May 2010

Published: 24 May 2010

\section{References}

1. Resnikoff S, Pascolini D, Etya'ale D, Kocur I, Pararajasegaram R, Pokharel GP, Mariotti SP: Global data on visual impairment in the year 2002. Bull World Health Organ 2004, 82:844-851.

2. Luo BP, Brown GC, Luo SC, Brown MM: The quality of life associated with presbyopia. Am J Ophthalmol 2008, 145:618-622

3. McDonnell PJ, Lee P, Spritzer K, Lindblad AS, Hays RD: Associations of presbyopia with vision-targeted health-related quality of life. Arch Ophthalmol 2003, 121:1577-1581.

4. Oshika T, Sugita G, Hayashi K, Eguchi S, Miyata K, Kozawa T, Oki K: [Influence of cataract and intraocular lens surgery on health-related quality of life]. Nippon Ganka Gakkai Zasshi 2005, 109:753-760.

5. Canadanovic V, Latinovic S, Babic N, Babovic S, Zikic Z, Ljesevic L, Grkovic D, Bedov T: Quality of Life in Patients with Cataract VQOL Study Group Report. Patient Reported Outcomes Newsletter 1994:23-24

6. Knudtson MD, Klein BE, Klein R, Cruickshanks KJ, Lee KE: Age-related eye disease, quality of life, and functional activity. Arch Ophthalmol 2005, 123:807-814.

7. Cataracts [http://www.mayoclinic.com/health/cataracts/DS00050] 
8. Tewari A, Shah GK: Presbyopia-correcting intraocular lenses: what retinal surgeons should know. Retina 2008, 28:535-537.

9. Gatinel D: [Presbyopia surgery]. Rev Prat 2008, 58:1049-1054.

10. Berdeaux G, Viala M, Roborel de CA, Arnould B: Patient-reported benefit of ReSTOR multi-focal intraocular lenses after cataract surgery: results of principal component analysis on clinical trial data. Health Qual Life Outcomes 2008, 6:10.

11. Cabezas-Leon M, Gracia-San RJ, Garcia-Caballero J, Morente-Matas P: [Quality of life following cataract surgery]. Arch Soc Esp Oftalmol 2005, 80:449-456

12. Cabezas-Leon M, Garcia-Caballero J, Morente-Matas P: [Impact of cataract surgery on visual acuity and quality of life]. Arch Soc Esp Oftalmol 2008, 83:237-247.

13. Chandrasekaran S, Wang JJ, Rochtchina E, Mitchell P: Change in healthrelated quality of life after cataract surgery in a population-based sample. Eye 2008, 22:479-484

14. Chiam PJ, Chan JH, Aggarwal RK, Kasaby S: ReSTOR intraocular lens implantation in cataract surgery: quality of vision. J Cataract Refract Surg 2006, 32:1459-1463.

15. Pesudovs $\mathrm{K}$, Weisinger HS, Coster DJ: Cataract surgery and changes in quality of life measures. Clin Exp Optom 2003, 86:34-41.

16. Souza CE, Muccioli C, Soriano ES, Chalita MR, Oliveira F, Freitas LL, Meire $L P$, Tamaki C, Belfort R Jr: Visual performance of AcrySof ReSTOR apodized diffractive IOL: a prospective comparative trial. Am J Ophthalmol 2006, 141:827-832.

17. Bi H, Cui Y, Ma X, Cai W, Wang G, Ji P, Xie X: Early clinical evaluation of AcrySof ReSTOR multifocal intraocular lens for treatment of cataract. Ophthalmologica 2008, 222:11-16.

18. Blaylock JF, Si Z, Vickers C: Visual and refractive status at different focal distances after implantation of the ReSTOR multifocal intraocular lens. $J$ Cataract Refract Surg 2006, 32:1464-1473.

19. Kohnen T, Allen D, Boureau C, Dublineau P, Hartmann C, Mehdorn E, Rozot P, Tassinari G: European multicenter study of the AcryS of ReSTOR apodized diffractive intraocular lens. Ophthalmology 2006, 113:584.

20. Souza CE, Gerente VM, Chalita MR, Soriano ES, Freitas LL, Belfort R Jr: Visual acuity, contrast sensitivity, reading speed, and wavefront analysis: pseudophakic eye with multifocal IOL (ReSTOR) versus fellow phakic eye in non-presbyopic patients. J Refract Surg 2006, 22:303-305.

21. Alfonso JF, Fernandez-Vega L, Senaris A, Montes-Mico R: Prospective study of the Acri. LISA bifocal intraocular lens. J Cataract Refract Surg 2007, 33:1930-1935

22. Alio JL, Tavolato M, De la HF, Claramonte P, Rodriquez-Prats JL, Galal A: Near vision restoration with refractive lens exchange and pseudoaccommodating and multifocal refractive and diffractive intraocular lenses: comparative clinical study. J Cataract Refract Surg 2004, 30:2494-2503.

23. Cillino S, Casuccio A, Di PF, Morreale R, Pillitteri F, Cillino G, Lodato G: Oneyear outcomes with new-generation multifocal intraocular lenses. Ophthalmology 2008, 115:1508-1516.

24. Mester U, Hunold W, Wesendahl T, Kaymak H: Functional outcomes after implantation of Tecnis ZM900 and Array SA40 multifocal intraocular lenses. J Cataract Refract Surg 2007, 33:1033-1040.

25. Montes-Mico R, Alio JL: Distance and near contrast sensitivity function after multifocal intraocular lens implantation. J Cataract Refract Surg 2003, 29:703-711.

26. Javitt JC, Wang F, Trentacost DJ, Rowe M, Tarantino N: Outcomes of cataract extraction with multifocal intraocular lens implantation: functional status and quality of life. Ophthalmology 1997, 104:589-599.

27. Steinberg EP, Tielsch JM, Schein OD, Javitt JC, Sharkey P, Cassard SD, Legro MW, Diener-West M, BASS EB, Damiano AM, et al:: The VF-14: An Index of Functional Impairment in Patients with Cataract. Archives of Ophthalmology 1994, 112:630-638.

28. Pesudovs K, Garamendi E, Elliott DB: The Quality of Life Impact of Refractive Correction (QIRC) Questionnaire: development and validation. Optom Vis Sci 2004, 81:769-777.

29. Pesudovs K, Garamendi E, Elliott DB: The Contact Lens Impact on Quality of Life (CLIQ) Questionnaire: development and validation. Invest Ophthalmol Vis Sci 2006, 47:2789-2796

30. Day H, Jutai J, Campbell KA: Development of a scale to measure the psychosocial impact of assistive devices: lessons learned and the road ahead. Disability and Rehabilitation 2002, 24:31-37.
31. Levy P, Elies D, Dithmer O, Gil-Campos I, Benmedjahed K, Berdeaux G, Arnould B: Development of a new subjective questionnaire: The Freedom from Glasses Value Scale (FGVS). Journal of Refractive Surgery [http://www.journalofrefractivesurgery.com/preprint.asp]. Posted online August 3, 2009

32. Hays RD, Hayashi $\mathrm{T}$ : Beyond internal consistency reliability: rationale and user's guide for Multitrait analysis program on the microcomputer. Behav Res Methods Instrum Comput 1990, 22:167-175.

33. Cronbach $\sqcup$ : Coefficient Alpha and the Internal Structure of Tests. Psychometrika 1951, 16:297-334.

34. Nunnally JC, Bernstein IH: Psychometric theory New York: McGraw-Hill Inc; 1994.

35. Paulhus DL: Measurement and control of response bias. In Measures of personality and social psychological attitudes Volume 1. Edited by: Robinson JP, Shaver P, Wrightsman LS. San Diego, CA: Academic Press; 1991:17-59.

36. Bentler PM, Jackson DN, Messick S: Identification of content and style: a two-dimensional interpretation of acquiescence. Psychol Bull 1971, 76:186-204

37. Schuman H, Presser S: Questions and answers in attitude surveys: Experiments on question form, wording, and context Thousand Oaks, CA: Sage Publications; 1981

38. van Herk $\mathrm{H}$, Poortinga $\mathrm{YH}$, Verhallen TMM: Response styles in rating scales: evidence of method bias in data from six EU countries. Journa of Cross-Cultural Psychology 2004, 25:346-360.

39. Hofstede GH: Culture's consequences: Comparing values, behaviors, institutions, and organizations across nations Thousand Oaks, CA: Sage Publications; 2001

40. Johnson T, Kulesa P, LIC I, Cho YI, Shavitt S: The relation between culture and response styles: evidence from 19 countries. Journal of CrossCultural Psychology 2005, 36:264-277.

Pre-publication history

The pre-publication history for this paper can be accessed here: http://www.biomedcentral.com/1471-2415/10/15/prepub

doi: $10.1186 / 1471-2415-10-15$

Cite this article as: Berdeaux et al., Measuring benefits and patients' satisfaction when glasses are not needed after cataract and presbyopia surgery: scoring and psychometric validation of the Freedom from Glasses Value Scale (FGVS๑) BMC Ophthalmology 2010, 10:15

\section{Submit your next manuscript to BioMed Centra and take full advantage of:}

- Convenient online submission

- Thorough peer review

- No space constraints or color figure charges

- Immediate publication on acceptance

- Inclusion in PubMed, CAS, Scopus and Google Scholar

- Research which is freely available for redistribution 